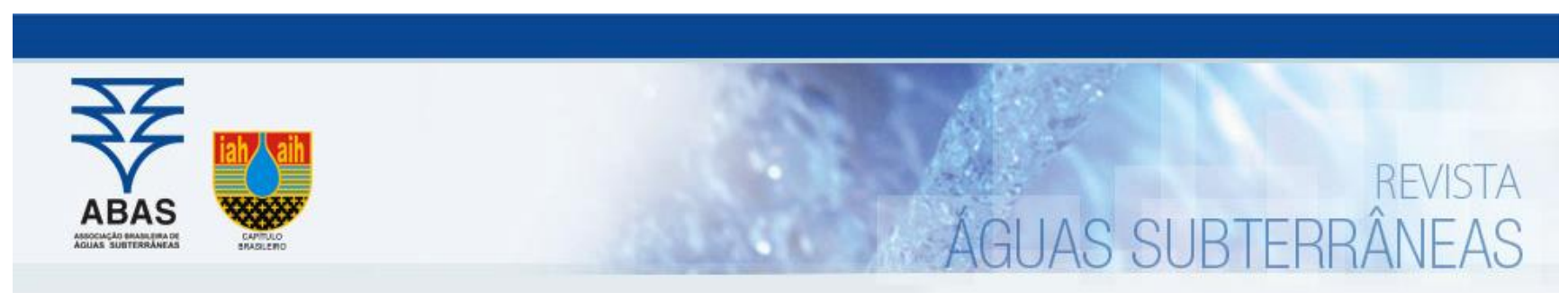

Artigos

\title{
Caracterização hidráulica das camadas de um pavimento permeável
}

\section{Hydraulic characterization of the layers of a permeable pavement}

\author{
Artur Paiva Coutinho; Tássia dos Anjos Tenório de Melo² ; Lucas Ravellys Pyrrho de Alcântara2 ; Ana Emília Carvalho de \\ Gusmão da Cunha Rabelo2 ; Severino Martins dos Santos Neto2 ; Antonio Celso Dantas Antonino ${ }^{凶}$ \\ 1 Universidade Federal de Pernambuco (UFPE) - Campus do Agreste, Caruaru, PE \\ 2 Universidade Federal de Pernambuco (UFPE) - Recife, PE \\ $\llbracket$ arthur.coutinho@yahoo.com.br, melo.tassia@yahoo.com.br, ravellyspyrrho@gmail.com, anaerabelo@gmail.com, martinsdsn@gmail.com, \\ acdantonino@gmail.com \\ Palavras-chave: \\ Infiltração. \\ Melhores Práticas de Manejo. \\ Método Beerkan. \\ Hydrus.

\begin{abstract}
Resumo
Os pavimentos permeáveis (PPs) são alternativas que reduzem os volumes dos hidrogramas de escoamento superficial gerados, além de favorecer a recarga dos aquíferos. Foi instalado um sítio experimental na cidade do Recife para zação hidrodinâmica e avaliar a infiltração do revestimento e do subleito de um pavimento permeável a partir da metodologia Beerkan. Com isso foi possível simular o comportamento hidráulico do PP quando solicitado a um fluxo de subleito e a metodologia utilizada permitiu um entendimento isolado das propriedades de cada componente e uma compreensão conjunta do funcionamento hidráulico do dispositivo.
\end{abstract} \\ estudo da técnica de PP com blocos vazados para amortecimento de alagamentos. 0 objetivo foi realizar a caracteri- \\ escoamento superficial. Assim, conclui-se que o revestimento apresentou uma capacidade de infiltração maior que o
}

Keywords:

Infiltration.

Best Management Practices.

Beerkan Methodology.

Hydrus.

Revisado por pares.

Recebido em: 03/07/2019.

Aprovado em: 16/06/2020.
Abstract

Infiltration systems such as permeable pavements (PPs) are alternatives that allow a reduction of the volume of the generated runoff hydrographs, and the pollutant load. Besides that they promote groundwater recharge. An experimental site was installed in the city of Recife to study the PP technique using hollow blocks for damping flooding. The aim of this paper is to present the hydrodynamic characterization and analyse the infiltration of the coating and subgrade layer in a PP through the Beerkan methodology. This characterization allows the simulation of the PP hydraulic behavior when applied to a surface runoff flow. Thus, it was concluded that the coating layer had an infiltration capability higher than the subgrade. The methodology leaded to an isolated understanding of each component properties and a joint understanding of the device hydraulic operation.

DOI: http:/dx.doi.org/10.14295/ras.v34i2.29575

\section{INTRODUÇÃO}

O processo de urbanização que ocorre nas cidades, quando desordenadamente, é proporcional à substituição das superfícies permeáveis por impermeáveis, resultando, principalmente, na diminuição das taxas de infiltração das águas pluviais, nos aumentos do volume e velocidade do escoamento superficial e, consequentemente, na intensificação dos alagamentos e inundações. Estudos ao redor do mundo têm reportado estes impactos negativos (LIMTHONGSAKUL et al, 2017; BAl et al., 2018; LIU et al., 2018; ZHU et al., 2019), e muitas cidades brasileiras têm experimentado os reflexos desses desequilíbrios do ciclo hidrológico (SANTOS et al., 2017; HOLANDA; SOARES, 2019).

As técnicas compensatórias para a drenagem urbana (pavimento poroso, trincheiras de infiltração, jardins de chuva) bus- cam resgatar uma condição próxima ao natural para a infiltração nas bacias hidrográficas, reduzindo os impactos nas áreas urbanas através da promoção sustentável da gestão das águas pluviais (BONNEAU et al., 2017; Ll et al., 2019).

Superfícies composta por revestimentos como concreto poroso, asfalto poroso e blocos intertravados (vazados ou não vazados) são alternativas contidas nos conceitos das Best Management Practices (BMPs, em tradução literal Melhores Práticas de Manejo). Essas boas práticas de manejo visam aproximar as condições de infiltração do solo e escoamento superficial àquelas situações de pré-ocupação urbana do solo (JÁBUR et al., 2015; WINSTON et al., 2016; KUMAR et al., 2016), compensando os impactos negativos advindos do processo de urbanização, associados ao ciclo hidrológico.

Pavimento permeável (PP) consiste em um dispositivo de infil- 
tração que age como um condutor de parte do escoamento superficial, desviando-o para um reservatório de elevada porosidade e permeabilidade em subsuperfície (JABUR et al., 2015; RODRÍGUEZ-ROJAS et al., 2018; ZHU et al., 2019). A sua utilização em áreas urbanas visa melhorar a qualidade da água, auxiliando na remoção de sólidos em suspensão, fósforo e metais pesados (LIU et al., 2019), e contribuir para o aumento da recarga da água subterrânea (KUMAR et al., 2016; ZHU et al., 2019; LI et al., 2019).

Porém, devido a variabilidade de poluentes que podem estar contidos nas águas pluviais e, consequentemente no escoamento superficial, como materiais em suspensão, materiais orgânicos - bactérias, hidrocarbonetos, metais pesados e poluentes microbiológicos - coliformes fecais (LIU et al., 2019; SELBIG et al., 2019; JAYARATHNE et al., 2020), é recomendável compreender o comportamento dos poluentes e os impactos desses nas águas e no solo para garantir o uso seguro do sistema para fins de recarga subterrânea ou outra reutilização.

Segundo Jabur et al. (2015), os pavimentos podem ser identificados em três níveis diferentes de atuação no controle da produção do escoamento superficial: i) pavimentos dotados de revestimentos superficiais permeáveis; ii) pavimentos dotados de estrutura porosa; iii) pavimentos dotados de estrutura porosa e de dispositivos de facilitação da infiltração.

Os pavimentos permeáveis apresentam as seguintes vantagens: redução do escoamento superficial relacionado à produção por superfícies impermeáveis; redução do diâmetro dos condutos da drenagem pluvial; redução dos custos do sistema de drenagem pluvial; redução da lâmina de água em estacionamentos e passeios; melhoria da qualidade da água durante o processo de infiltração e retenção de poluentes como zinco, nitratos e compostos de fósforos, através da camada superficial - revestimento, e das camadas intermediárias compostas, geralmente, por cascalho, areia ou brita (DRAKE et al., 2014; PAGE et al., 2015; NNADI et al., 2015; JIANG et al., 2015; LIU et al., 2019).

No entanto, a técnica de pavimentos permeáveis apresenta necessidade de manutenção periódica do sistema para evitar que a camada de revestimento fique colmatada com o tempo; maior custo de construção, desconsiderando o benefício de redução dos condutos; e acarreta maior risco de contaminação dos aquíferos, principalmente quando implantados em estacionamentos, devido à qualidade do escoamento nessas áreas pela presença de poluentes como metais pesados (DRAKE et al., 2014; JABUR et al., 2015; CHANDRAPPA et al., 2016; CHU et al., 2019).

0 projeto dos sistemas de infiltração requer o conhecimento de propriedades hidráulicas do solo suporte, as quais estão diretamente relacionadas com a textura, estrutura e uso do solo. Nos últimos anos, gradativamente, a questão da infiltração em áreas urbanas tem recebido mais atenção.

Trabalhos científicos como os de Jabur et al. (2015), Kumar et al. (2016) e Winston et al. (2016) têm abordado questões referentes ao desempenho de diferentes superfícies permeáveis como o concreto poroso, asfalto poroso e blocos intertravados e, os efeitos de alguns aspectos construtivos como compactação da base e influência da declividade do terreno.

Turco et al. (2017) construíram um pavimento permeável em escala de laboratório e mediram experimentalmente as propriedades hidrodinâmicas dos materiais utilizados na construção das 3 camadas que compõem o sistema. Além disso, utilizaram modelagem computacional no modelo Hydrus 2-D para interpretar o comportamento hidráulico do pavimento permeável.

Kumar et al. (2016) analisaram o desempenho da infiltração medida em três seções de pavimento permeável (bloco intertravado, concreto permeável e asfalto permeável), e verificaram um declínio na taxa de infiltração ao longo do tempo devido ao entupimento dos poros. No entanto, os autores observaram que a taxa de infiltração se manteve de quatro a cinco vezes maior que a intensidade média da precipitação na região.

Este artigo apresenta a caracterização hidrodinâmica das camadas estruturais de um pavimento permeável composto por blocos vazados implantado experimentalmente na cidade do Recife / PE, Nordeste brasileiro.

\section{MATERIAIS E MÉTODOS}

\section{1. Área de estudo}

O sítio experimental foi instalado no estacionamento do Centro de Tecnologia e Geociências (CTG) da Universidade Federal de Pernambuco (UFPE), na cidade do Recife, aproximadamente a 4 metros acima do nível do mar. 0 clima na região, pela classificação de Köppen, é do tipo As (clima tropical com estação seca de verão), com estação chuvosa no período de inverno, com maiores precipitações nos meses de abril a juIho, correspondendo a $70 \%$ do total precipitado anualmente (MEDEIROS et al., 2018; ALCÂNTARA et al., 2019). De acordo com Cabral e Montenegro (2004) a evaporação média mensal é de 110,3 mm com valor máximo em dezembro (146,3 mm). Os dados de chuva na estação Várzea pertencente à rede de monitoramento da Agência Pernambucana de Águas e Clima - APAC para o período de 1994 a 2010, apresentam média anual de 2.173,8 mm (Figura 1). 
Figura 1 - Precipitação média mensal para a cidade do Recife, estação Várzea no período 1994- 2010

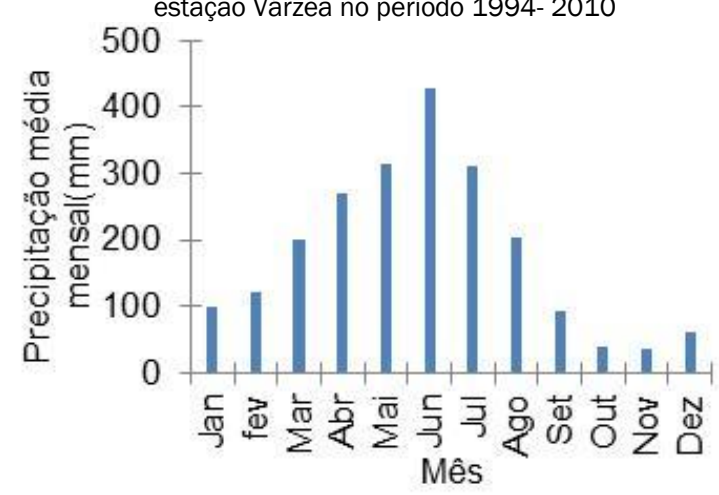

Fonte: Adaptado de APAC (2020)

\subsection{Descrição do pavimento permeável piloto}

O PP foi construído objetivando compensar uma área impermeável de $110 \mathrm{~m}^{2}$, referente ao estacionamento do Centro de Tecnologia e Geociências (CTG-UFPE).

O pavimento permeável piloto possui as seguintes dimensões: 3,00 m de comprimento; $1,50 \mathrm{~m}$ de largura; e 0,64 $\mathrm{m}$ de profundidade, formado por um revestimento de 0,09 $\mathrm{m}$ de espessura, uma camada de areia grossa com 0,05 m de espessura, uma camada de reservatório com $0,40 \mathrm{~m}$ de espessura e preenchida com brita de porosidade $43 \%$, e outra camada de areia grossa com $0,10 \mathrm{~m}$ de espessura.

O reservatório é revestido por mantas drenantes (geotêxtil) nas porções inferior e superior, evitando o contato direto deste com as camadas de areia. A composição estrutural do pavimento permeável piloto é ilustrada na Figura 2.

Figura 2 - Composição estrutural do pavimento permeável piloto. Medidas em metros

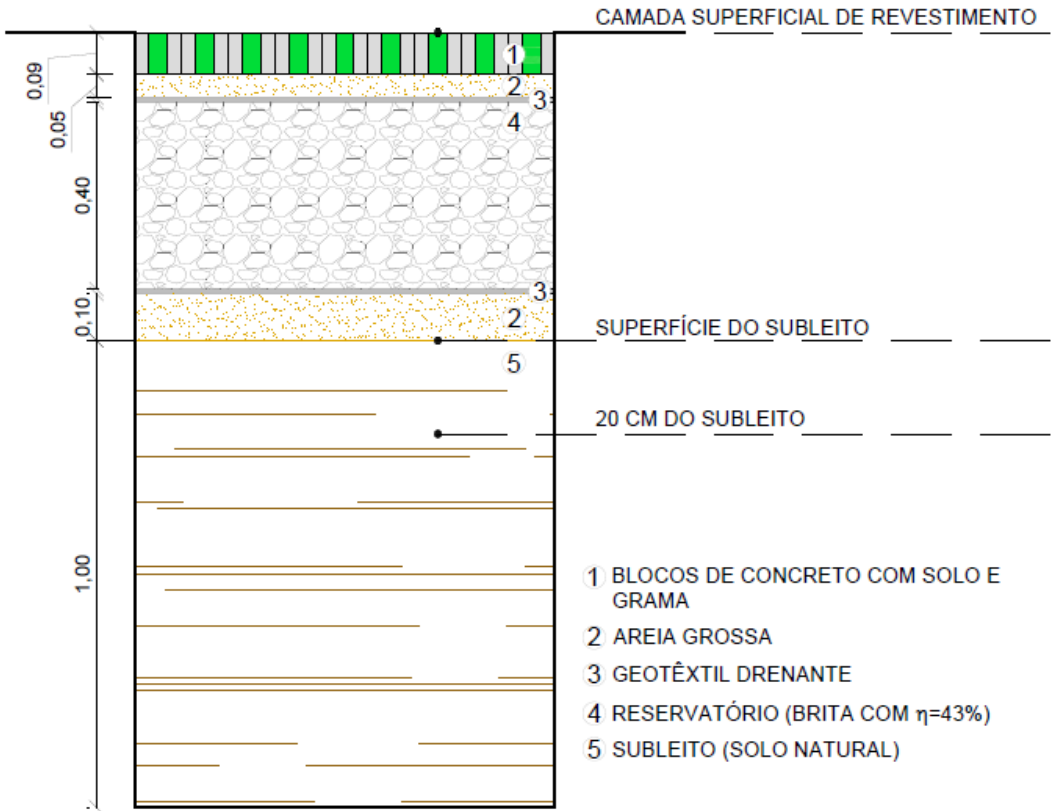

\subsection{Caracterização dos solos e ensaios de infiltração}

A camada do revestimento apresenta elevada importância por estar diretamente sujeita às ações mecânicas oriundas do tráfego de veículos leves e por ser responsável pela captação da água do escoamento superficial através do processo de infiltração.

Foram realizados ensaios de curva de retenção e granulometria segundo a NBR 7181 (ABNT, 2016) para caracterização do solo utilizado no preenchimento dos blocos intertravados e da camada do subleito do pavimento permeável. Para o subleito, foram retiradas amostras deformadas a cada $10 \mathrm{~cm}$ a partir da superfície do subleito até a profundidade de um metro.

Para a determinação da densidade do solo e da curva de retenção foram coletadas amostras indeformadas por meio de amostrador de solo, tipo Uhland. Os ensaios de infiltração nos solos foram realizados usando o infiltrômetro de anel simples aplicando a metodologia Beerkan descrita em Lassabatere et al. (2019). 
Para o ensaio de infiltração na superfície do pavimento permeável, a base do infiltrômetro foi vedada com silicone, a fim de evitar a dispersão lateral da infiltração.

Os ensaios foram realizados considerando as condições reais de campo, como a presença de folhas de árvores, sedimentos carreados pela água de escoamento superficial e resíduos sobre a superfície do pavimento.

\subsubsection{Método Beerkan}

Nesse método, as curvas de retenção $\theta(\mathrm{h})$ e de condutividade hidráulica $\mathrm{K}(\theta)$ do solo são descritas, respectivamente, pelos modelos de van Genutchen (1980) e de Brooks; Corey (1964), através das Equações 1 e 2.

$\left(\frac{\theta-\theta_{r}}{\theta_{s}-\theta_{r}}\right)=\left[1+\left(\frac{h}{h_{g}}\right)^{n}\right]^{m}$

com $m=1-\frac{2}{n}$ (Burdine, 1953)

$K(\theta)=K_{s}\left(\frac{\theta}{\theta_{s}}\right)^{\eta}$

Sendo $\theta$ é a umidade volumétrica $\left[\mathrm{cm}^{3} / \mathrm{cm}^{3}\right]$; $\theta$ s a umidade volumétrica saturada $\left[\mathrm{cm}^{3} / \mathrm{cm}^{3}\right]$; h é o potencial matricial [m]; $h_{\mathrm{g}}$ é o potencial de entrada de ar; $n$ e m são parâmetros de forma [adimensionais]; Ks é a condutividade hidráulica saturada [mm/s]; $\eta$ o parâmetro de forma [adimensional] para a curva de condutividade hidráulica. Essas funções contêm cinco parâmetros desconhecidos: dois de forma (m, n ou $\eta$ ) e três parâmetros de normalização ( $\theta \mathrm{s}, \mathrm{Ks}, \mathrm{hg})$.

Os parâmetros de forma são ligados à textura e possuem similaridade de forma entre a distribuição do tamanho das partículas F(D) e $\theta(h)$. Haverkamp; Parlange (1986) apresentaram a Equação 3 para expressar $F(D)$.

$F(D)=\left[1+\left(\frac{D_{g}}{D}\right)^{n}\right]^{-m}$

com $m=1-\frac{2}{n}$

Sendo D o diâmetro da partícula [mm]; Dg o parâmetro de escala do tamanho das partículas [mm]; $\mathrm{M}$ e $\mathrm{N}$ os parâmetros de forma da curva de distribuição do tamanho das partículas [adimensional].

Por sua vez, os parâmetros de normalização dependem da estrutura dos solos. Os parâmetros (hg, Ks) são obtidos por intermédio da minimização de I(S, Ks), ou seja, dos quadrados das diferenças entre as lâminas de água infiltradas observadas e calculadas. A lâmina de água infiltrada é calculada pela equação proposta por Haverkamp et al. (1994), válida para tempos curtos e médios (Equação 4).

$I\left(S, K_{S}\right)=\sum_{i=1}^{N o b s}\left(I_{i}-\left(S \cdot \sqrt{t_{i}}+a \cdot S^{2} \cdot t_{i}+b_{2} \cdot K_{s} \cdot t_{i}\right)\right)^{2}$

com:

$a=\frac{\gamma}{r . \Delta \theta}$

$b_{2}=\left(\frac{\theta_{0}}{\theta_{s}}\right)^{\eta}+\frac{2-\beta}{3} \cdot\left(1-\left(\frac{\theta_{0}}{\theta_{s}}\right)^{\eta}\right)$

Sendo $S$ a sorvidade; $r$ o raio do cilindro; $\gamma$ igual a 0,75 e $\beta$ igual a 0,6.
Segundo Lassabatere et al. (2019), durante o processo de infiltração tridimensional, alguns fatores podem afetar o fluxo de entrada de água no solo, destacando a geometria da fonte de água, a capilaridade e a gravidade. Uma das formas de caracterizar esses fatores é a partir das escalas de comprimento capilar ( $\lambda$ c) (WHITE; SULLY, 1987) e do raio característico dos poros hidraulicamente ativos $(\lambda \mathrm{m})$ (PHILIP, 1987), determinados pelas Equações 5 e 6, respectivamente:

$\lambda_{c}=\frac{\delta S^{3}}{\left(\theta_{s}-\theta_{0}\right) K_{s}}$

$\lambda_{m}=\frac{\sigma}{\rho_{a} g \lambda_{c}}$

Sendo $\sigma$ a tensão superficial da água $\left[0,0719 \mathrm{~N} \mathrm{~m}^{-1}\right] ; \rho_{a} a$ massa específica da água $\left[10^{3} \mathrm{Kg} \mathrm{m}^{-3}\right]$; g a aceleração da gravidade [9,81 $\left.\mathrm{m} \mathrm{s}^{-2}\right]$; $\delta$ um parâmetro de forma da difusividade $[1 / 2 \leq \delta \leq \pi / 4]$, o qual foi considerado igual a 0,55 (WHITE; SULLY, 1987).

Para Souza et al. (2008) a escala de comprimento capilar representa a importância relativa das forças capilares em relação a gravidade, quando a água é transmitida de uma fonte através do solo, com umidade inicial $\theta_{0}$. 0 raio característico de poros define a dimensão média dos poros que participam do processo de infiltração submetida a pressão aplicada $h$; quanto maior for o raio característico, $\lambda \mathrm{m}$, maior é o efeito da gravidade em comparação ao da capilaridade (SOUZA et al., 2007).

O número de poros $\mathrm{C}_{\lambda m}$ é estimado usando a lei de Poiseuille para fluxo em um tubo capilar (Equação 7).

$C_{\lambda m}=\frac{8 \mu K}{\rho_{a} g \pi \lambda_{m}{ }^{4}}$

Sendo $\mu$, a viscosidade dinâmica da água $\left[0,00089 \mathrm{~kg} \mathrm{~m}^{-1} \mathrm{~s}\right.$ 1].

\subsubsection{Modelagem bidimensional}

A modelagem bidimensional foi realizada com o modelo Hydrus-2D, para um fluxo bidimensional e aximétrico. 0 hydrus é um sistema computacional que simula a dinâmica da água em solos não saturados, resolvendo a Equação de Richards (Equação 8) utilizando a técnica dos elementos finitos (SIMUNEK et al., 2008).

$\frac{\partial \theta}{\partial t}=\frac{\partial}{\partial x_{i}}\left[K_{i j}^{A}\left(\frac{\partial h}{\partial x_{j}}+K_{i z}^{A}\right)\right]-S$

Sendo h o potencial mátricial [L]; $\theta$ a umidade volumétrica[ $\mathrm{L}^{3}$. $\mathrm{L}^{-3}$ ]; t o tempo [T]; $\mathrm{x}$ a coordenada espacial [L]; $\mathrm{S}$ o termo de sumidouro $\left[\mathrm{L}^{3} \cdot \mathrm{L}^{-3} \cdot \mathrm{T}^{-1}\right]$.

Neste modelo, $\theta(\mathrm{h})$ (Equações 9 e 10) e K(h) (Equação 11) são descritas pelo modelo de van Genutchen (1980) com a hipótese de distribuição dos poros de Mualem (1976).

$$
\begin{aligned}
& \theta(h)=\theta_{r}+\frac{\theta_{s}-\theta_{r}}{\left(1+|\alpha h|^{n}\right)^{m}} \quad \text { para } \quad \mathrm{h}<0 \\
& \theta(h)=\theta_{s} \text { para } \mathrm{h}>0 \\
& K(h)=K_{s} \cdot S_{e}^{0,5}\left(1-\left(1-S_{e}^{\frac{1}{m}}\right)^{m}\right)^{2} \\
& \operatorname{com} m=1-\frac{1}{n}
\end{aligned}
$$


Para simular cenários do comportamento hidráulico do perfil do pavimento permeável, as condições atmosféricas foram utilizadas como condição de fronteira superior. A série de pre-

cipitação simulada foi de 365 dias (Figura 3A), referente ao ano de 2011, com dados da estação Várzea da APAC (APAC, 2020), por ser o ano com maior índice de pluviométrico dos últimos 15 anos (2005 - 2019). Assim, o escoamento superficial gerado foi convertido em fluxo de entrada no dispositivo
(Equação 12). Para a condição de contorno inferior foi adotada a drenagem livre (Figura $3 \mathrm{~B}$ ).

$F=P+\frac{C \cdot P \cdot A_{\text {cap }}}{A_{\text {pav }}}$

Sendo $\mathrm{C}$ o coeficiente de escoamento superficial [adimensional]; $P$ a precipitação pluviométrica diária [mm]; $A_{c a p}$ a área de captação da precipitação pluviométrica [m²]; $A_{\text {pav }}$ a área superficial do pavimento permeável piloto $\left[\mathrm{m}^{2}\right]$.

Figura 3 - Precipitação e fluxo de escoamento superficial utilizados como condição de contorno superior (A), Condições de fronteiras aplicada no pavimento permeável (B) e Condições iniciais aplicadas no pavimento permeável (C)

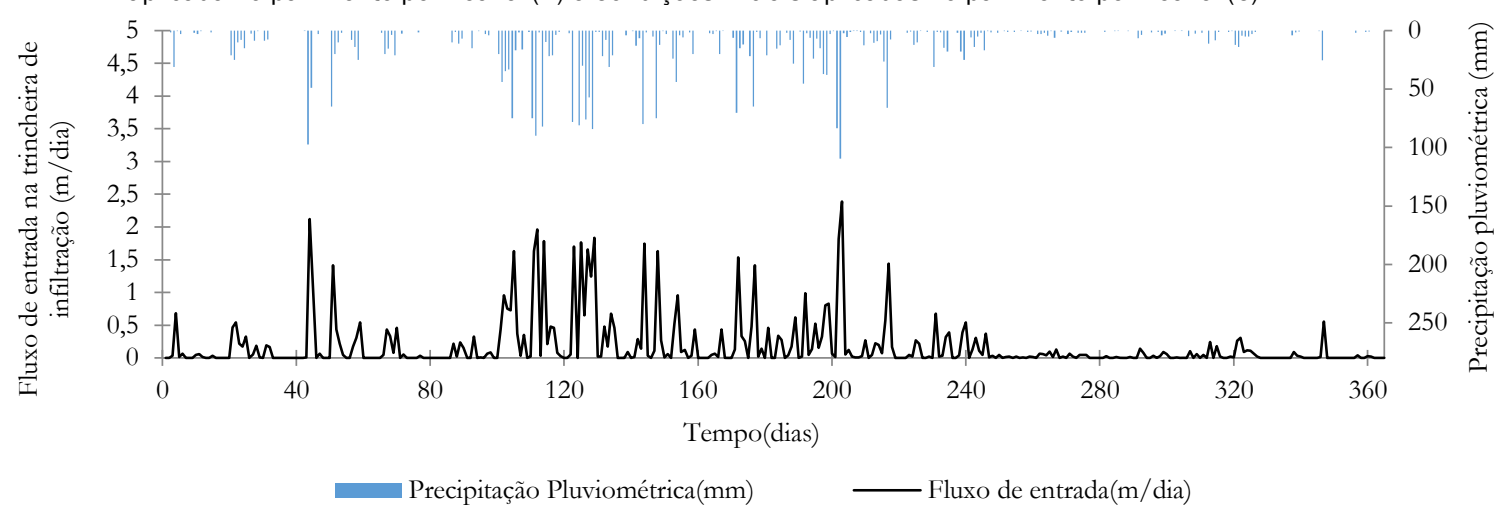

(A)

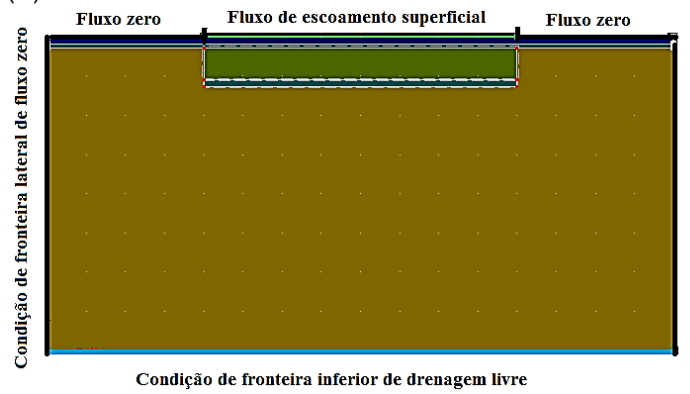

(B)

Como condição inicial foi arbitrado um valor de $100 \mathrm{cmH}_{2} \mathrm{O}$ para o dia 1, a partir dessa condição, foi simulada a seção da Figura 3B para o fluxo demonstrado na Figura 3A, finalmente, adotou-se como condição inicial definitiva a carta de potencial total obtida para o dia 365 dessa simulação, conforme demonstrado na Figura 3C.

\section{RESULTADO E DISCUSSÃO}

Neste item serão discutidos os resultados e discussões destas pesquisas, divididos em caracterização dos solos e ensaios de infiltração e na modelagem bidimensional de fluxo.

\subsection{Caracterização dos solos e ensaios de infiltração}

Foi observada a predominância de condições mais arenosas no material de revestimento do pavimento, no que diz respeito à granulometria do solo, sendo 84,29\% de areia, 8,68\% de argila e $7,03 \%$ de silte. No subleito, predominam os diâmetros das partículas de areia com porcentagens sempre acima de $70 \%$, sendo as profundidades de 30 e $40 \mathrm{~cm}$, as que apresentavam maior percentagem de areia (Figura 4).

O baixo percentual de argila e silte aponta uma classificação hidrológica do solo, de acordo com os critérios do Soil Conservation Service (SCS, 1972), nas categorias A ou B, r epresen-

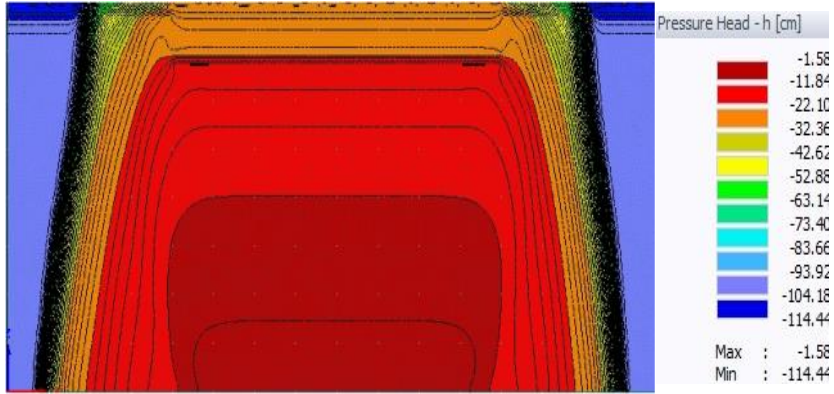

(C)

tando um solo com capacidade de infiltração acima da média. No entanto, para realizar tal afirmação torna-se necessário conhecer as características de infiltração do solo, uma vez que apenas a informação relativa à textura não é suficiente para indicar, com confiabilidade, as condições de infiltração e redistribuição de água no solo.

Outros fatores como quantidade matéria orgânica, a cobertura vegetal do sistema e fatores pedológicos podem interferir na caracterização dos processos hidrodinâmicos da água no solo, principalmente a infiltração (MORAIS, 2012). Porém compreender o funcionamento hidráulico do pavimento permeável piloto, de forma geral, é o foco deste trabalho. Compreendendo a eficiência hidrológica do sistema, sob a ótica quantitativa neste caso, é possível conduzir trabalhos futuros sobre como os fatores citados podem influenciar nos processos hidrodinâmicos no sistema e como se relacionam.

A classificação textural, a massa específica do solo e a massa específica das partículas para as profundidades de 0 a 100 centímetros do subleito do pavimento permeável são apresentadas na Tabela 1.

Com relação à curva de retenção, a figura 5 apresenta o comportamento para o solo da camada de revestimento do pavi- 


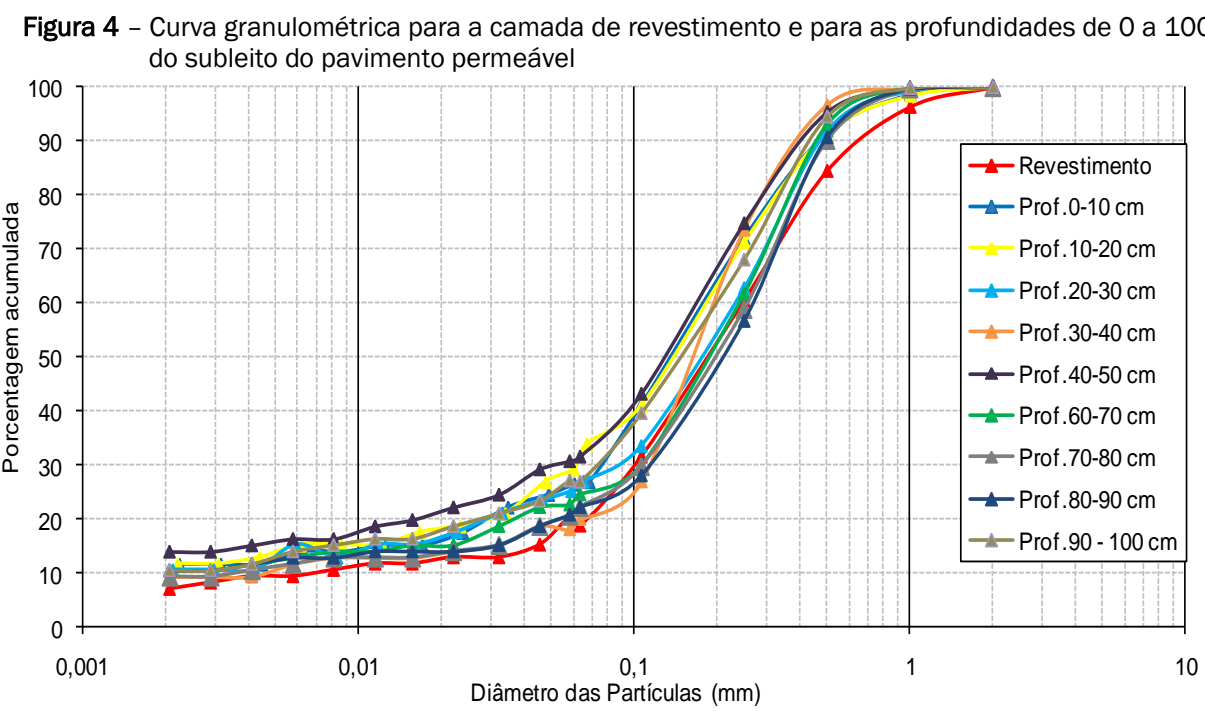

Tabela 1 - Camada, classificação textural (CF), massa específica do solo, massa específica das partículas do solo $(\rho s)$ e porosidade para os solos do revestimento e subleito do pavimento permeável( $(\eta)$

\begin{tabular}{ccccc}
\hline Camadas $(\mathrm{cm})$ & CF & $\rho_{\mathrm{s}}\left(\mathrm{g} / \mathrm{cm}^{3}\right)$ & $\rho_{\mathrm{p}}\left(\mathrm{g} / \mathrm{cm}^{3}\right)$ & $\eta(\%)$ \\
\hline Revestimento & AF & 1,1 & 2,66 & 58,64 \\
$0-10$ & AF & 1,33 & 2,64 & 49,62 \\
$10-20$ & AF & 1,48 & 2,68 & 44,78 \\
$20-30$ & AF & 1,46 & 2,62 & 44,27 \\
$30-40$ & AF & 1,4 & 2,64 & 46,97 \\
$40-50$ & FA & 1,35 & 2,58 & 47,67 \\
$50-60$ & AF & 1,4 & 2,64 & 46,97 \\
$60-70$ & AF & 1,7 & 2,6 & 34,62 \\
$70-80$ & AF & 1,58 & 2,675 & 40,93 \\
$80-90$ & AF & 1,47 & 2,61 & 43,6 \\
$90-100$ & AF & 1,55 & 2,60 & 40,38 \\
\hline
\end{tabular}

AF - Areia Franca, FA - Franco Arenoso

Figura 5 - Curva de retenção obtida experimentalmente para o solo da camada de revestimento do pavimento permeável

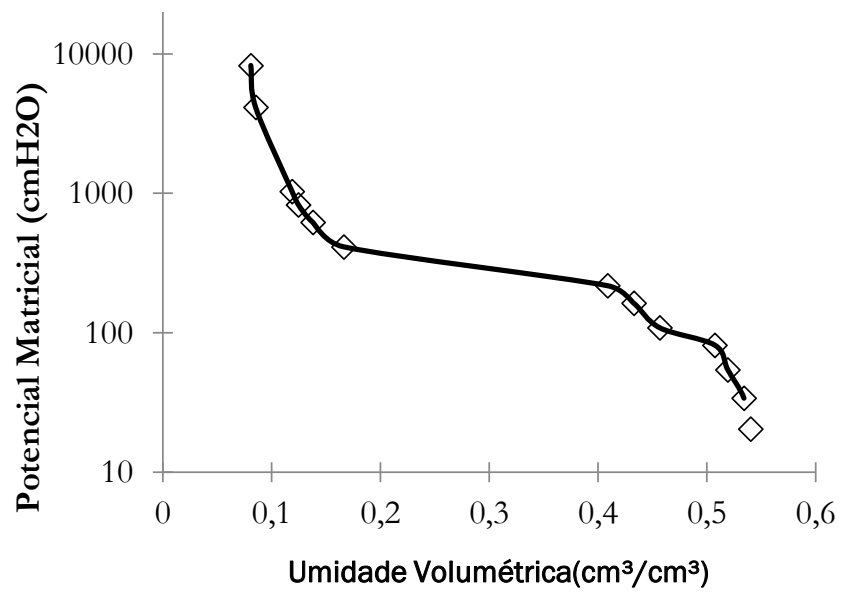


Com relação à infiltração acumulada, o ensaio apresentou uma lâmina infiltrada de $237,67 \mathrm{~mm}$ em 51,5 minutos $(0,85$ h) na camada superficial de revestimento (Figura $6 \mathrm{~A}$ ), e 71,3 mm em 120,45 minutos ( $2 \mathrm{~h}$, aproximadamente) na superfície do subleito (Figura 6B). Já na camada de $20 \mathrm{~cm}$ do subleito (Figura 6C) foi observada uma lâmina infiltrada de $59,47 \mathrm{~mm}$ em 96,41 minutos (1,61 h).

Figura 6 - Infiltrações acumuladas na camada superficial do revestimento (A); na superfície do subleito (B); e na camada a $20 \mathrm{~cm}$ do subleito $(\mathrm{C})$.

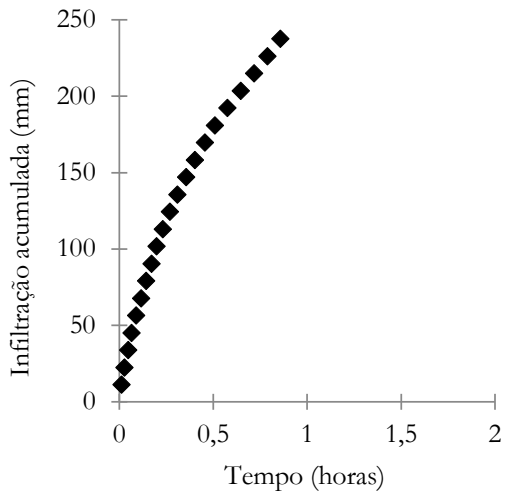

(A)

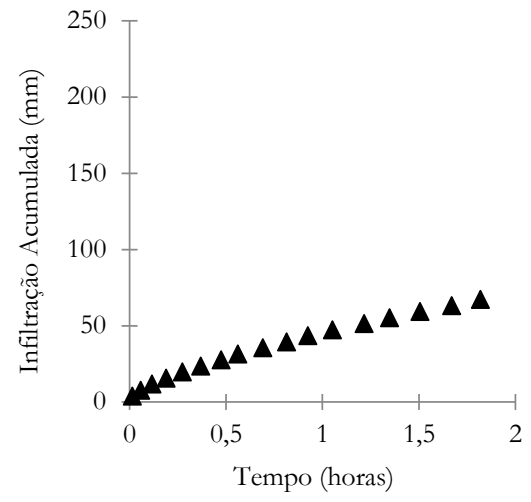

(B)

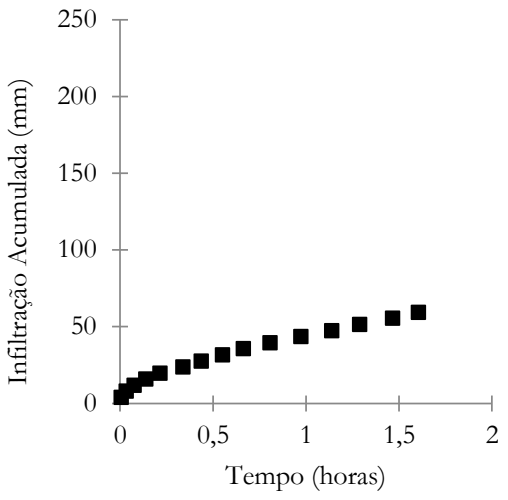

(C)
A aplicação da Equação 3 aos dados medidos das curvas granulométricas (Figura 4) resultou nos parâmetros de distribuição das partículas (M, N, Dg), conforme a Tabela 2. Na Tabela 2 também se observam os valores dos parâmetros de forma ( $m, n$ e $\eta$ ). Esses valores estão de acordo com os obtidos por Souza et al. (2008), os quais obtiveram valores de 0,13 (m);
2,31 (n) e 9,54 (n) para uma areia franca em uma parcela de solo no Estado da Paraíba. Gomes et al. (2015) também verificaram valores similares para um solo da microrregião de Garanhuns do tipo areia franca, com $\mathrm{m}, \mathrm{n}$ e $\eta$ sendo 0,$126 ; 2,28$ e 8,227, respectivamente.

Tabela 2 - Parâmetros de forma da curva de distribuição das partículas e das relações $h(\theta)$ e $K(\theta)$.

\begin{tabular}{ccccccccccc} 
Camada & Classe do solo & M & N & M.N & Dg $(\mathrm{mm})$ & Classe textural & m & n & $n$ \\
\hline Revestimento & AF & 0,277 & 2,767 & 0,76741 & 0,373 & Areia franca & 0,144 & 2,337 & 8,931 \\
Superfície do subleito & AF & 0,222 & 2,572 & 0,57205 & 0,455 & Areia franca & 0,122 & 2,279 & 10,168 \\
$20 \mathrm{~cm}$ do subleito & AF & 0,196 & 2,487 & 0,48738 & 0,468 & Areia franca & 0,112 & 2,253 & 10,913
\end{tabular}

São apresentados na Tabela 3, os valores de S, Ks, $\theta_{0}, \theta$ s, hg e $\lambda \mathrm{m}$ para solos da camada de revestimento, superfície do subleito e a $20 \mathrm{~cm}$ do subleito. Uma análise comparativa dessas propriedades mostra que a camada de revestimento apresenta valores de sorvidade e, principalmente, de condutivida- de hidráulica maiores que os apresentados para as demais camadas. No tocante ao material do subleito, as camadas analisadas apresentam valores muito próximos de condutividade hidráulica saturada e cerca de 4 vezes menor que o da camada de revestimento.

Tabela 3 - Valores de S, Ks, $\theta_{0}$, Өs e hg obtidos pela metodologia Beerkan para a camada do revestimento, superfície do subleito e a $20 \mathrm{~cm}$ do subleito do pavimento permeável

\begin{tabular}{cccc}
\hline Camada & Revestimento & Superfície do subleito & 20 cm do subleito \\
\hline $\mathrm{S}\left(\mathrm{mm}^{-0,5}\right)$ & 0,876 & 0,363 & 0,229 \\
$\mathrm{Ks}(\mathrm{mm} / \mathrm{s})$ & 0,015 & 0,004 & 0,004 \\
$\theta_{0}\left(\mathrm{~cm}^{3} / \mathrm{cm}^{3}\right)$ & 0,44 & 0,2 & 0,21 \\
$\Theta \mathrm{s}\left(\mathrm{cm}^{3} / \mathrm{cm}^{3}\right)$ & 0,57 & 0,45 & 0,38 \\
$\mathrm{hg}(\mathrm{m})$ & $-210,72$ & $-61,38$ & $-35,72$ \\
$\lambda \mathrm{m}(\mathrm{m})$ & 0,036 & 0,116 & 0,196 \\
$\mathrm{C} \lambda \mathrm{m}^{*}$ & $2,16.10^{6}$ & $4,97.10^{3}$ & $6,11.10^{2}$ \\
\hline
\end{tabular}

*Quantidade de poros hidraulicamente ativos por unidade de área $\left(\mathrm{n}^{\circ}\right.$ de poros $\left./ \mathrm{m}^{2}\right)$. 
A viabilidade para a construção do pavimento é garantida uma vez que os valores de condutividade se apresentam acima de $0,22 \mathrm{~mm} / \mathrm{s}(8 \mathrm{~mm} / \mathrm{h})$, valor recomendado por Azzout et al. (1994) como o mínimo viável em sistemas de infiltração. De acordo com a Tabela 4, o valor de Ks do revestimento $(0,015$ $\mathrm{mm} / \mathrm{s}$ ) garante a viabilidade do projeto.

Valores nessa ordem de grandeza foram encontrados por Zhu et al. (2019) que obtiveram taxas de 0,042 mm/s $(150 \mathrm{~mm} / \mathrm{h})$ para composto de asfalto poroso e $0,067 \mathrm{~mm} / \mathrm{s}(240 \mathrm{~mm} / \mathrm{h})$ para macadame. Hunt (2009) obteve valores médios em torno de $0,024 \mathrm{~mm} / \mathrm{s}(86 \mathrm{~mm} / \mathrm{h})$, atingindo um valor máximo de $0,053 \mathrm{~mm} / \mathrm{s}$ (188 mm/h) para superfícies permeáveis de blocos vazados (mesmo tipo utilizado nesta pesquisa). Importante informar que a metodologia desses trabalhos para quantificar a capacidade de infiltração do pavimento permeável se baseia na adaptação da norma ASTM D 3385 (ASTM, 2018), "Standard Test Method for Infiltratrion Rate in Field Soils Using Double - Ring Infiltrometer", adequando-a para superfícies pavimentadas.

0 raio característico de poros hidraulicamente funcionais $(\lambda \mathrm{m})$ apresentam valores que acompanham o crescimento da densidade dos solos, uma vez que a camada de revestimento, a camada da superfície do subleito e a camada a $20 \mathrm{~cm}$ do subleito apresentam densidades de $\left(1,1 ; 1,39\right.$ e 1,58 g/ $\left.\mathrm{cm}^{3}\right)$, respectivamente. No entanto, embora a camada de revestimento possua maior porosidade, o que é refletida pela sua densidade, a mesma possui uma dimensão média dos poros que participam do processo de infiltração menor que a dos solos do subleito. Esse resultado contrasta em parte com os obtidos por Souza et al. (2008) os quais observaram um aumento de Ks e $\mathrm{S}$ com um aumento de $\lambda \mathrm{m}$ e com a diminuição das massas específicas.

É importante observar que, apesar da camada de revestimento apresentar poros com dimensões menor $(0,036 \mathrm{~m})$ do que os da camadas da superfície do subleito $(0,116 \mathrm{~m})$ e de $2 \mathrm{~m} \mathrm{~cm}$ do subleito $(0,196 \mathrm{~m})$, o número de poros hidraulicamente ativos por unidade de área $\left(2,16.10^{6}\right)$ do revestimento é cerca de 1.000 vezes maior do que o da superfície do subleito $\left(4,97.10^{3}\right)$ e 10.000 vezes maior do que o apresentado para a profundidade de $20 \mathrm{~cm}$ do subleito $\left(6,11 \cdot 10^{2}\right)$.

O menor diâmetro dos poros existentes no revestimento é compensado pela sua elevada quantidade, de modo que na saturação a vazão transportada é maior. Isso explica o elevado valor da condutividade hidráulica saturada encontrada para essa camada, $0,015 \mathrm{~mm} / \mathrm{s}$, em relação ao valor de $0,004 \mathrm{~mm} / \mathrm{s}$ para as demais camadas.

As análises das curvas de retenção calculadas mostram que, para um mesmo potencial matricial, a camada de revestimento apresenta maior capacidade de retenção de água do que as camadas do subleito. A diferença entre as curvas de retenção da superfície do subleito e a $20 \mathrm{~cm}$ do subleito é menor do que quando comparada a curva característica do revestimento (Figura 7). A maior capacidade de retenção d'água do revestimento se deve, provavelmente, ao teor de matéria orgânica existente na camada de revestimento, tendo uma elevada umidade inicial $\theta_{0}\left(0,44 \mathrm{~cm}^{3} / \mathrm{cm}^{3}\right)$.

Figura 7 - Curvas de retenção (A) e de condutividade hidráulica (B) obtidas pela metodologia Beerkan para as camadas do revestimento, superfície do subleito e a $20 \mathrm{~cm}$ do subleito para o pavimento permeável.

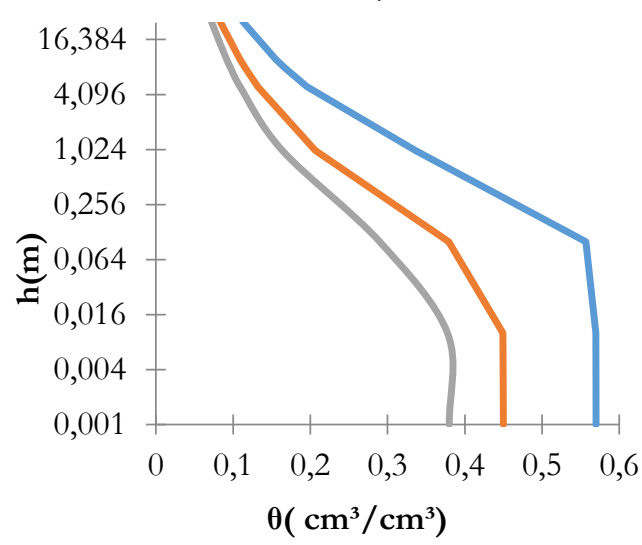

(A)

Na Figura 7, observam-se as curvas de condutividade hidráulica para as camadas do revestimento, da superfície do subleito e para a camada a $20 \mathrm{~cm}$ do subleito. Mesmo sem atingir o seu estado de saturação, o revestimento apresenta valores de condutividade hidráulica superiores ao Ks da camada do subleito, apresentando Ks em torno de $14 \mathrm{~mm} / \mathrm{h}$. Para valores menores de umidade volumétrica ou iguais a $0,45 \mathrm{~cm}^{3} / \mathrm{cm}^{3}$, as condutividades dos solos do subleito apresentam maiores do que a do revestimento.

Em geral, os fluxos de água do reservatório de brita para o

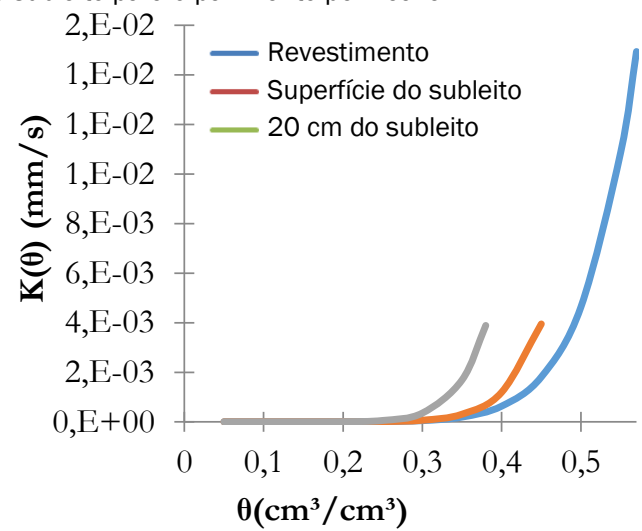

(B)

subleito foram menores do que as taxas de infiltração do revestimento para o interior do dispositivo. Araujo et al. (2000) citam que a capa de revestimento do pavimento poroso deve possuir uma taxa de infiltração típica de $3.800 \mathrm{~mm} / \mathrm{h}$. Jabur et al. (2015) observaram uma velocidade de infiltração básica no asfalto poroso de $250 \mathrm{~mm} / \mathrm{h}$ e $600 \mathrm{~mm} / \mathrm{h}$ para o bloco vazado.

A Figura 8 apresenta a diferença entre a curva característica obtida pelo Beerkan e a determinada experimentalmente para a camada de revestimento. Tomando a curva experimental 
como referência, observa-se que para cargas de sucção maiores do que $4 \mathrm{~m}$, a curva de retenção calculada pelo Beerkan apresenta valores de umidade maiores do que a curva experi- mental. Enquanto, para valores menores do que $4 \mathrm{~m}$, a curva obtida pelo Beerkan estima valores menores que o experimental.

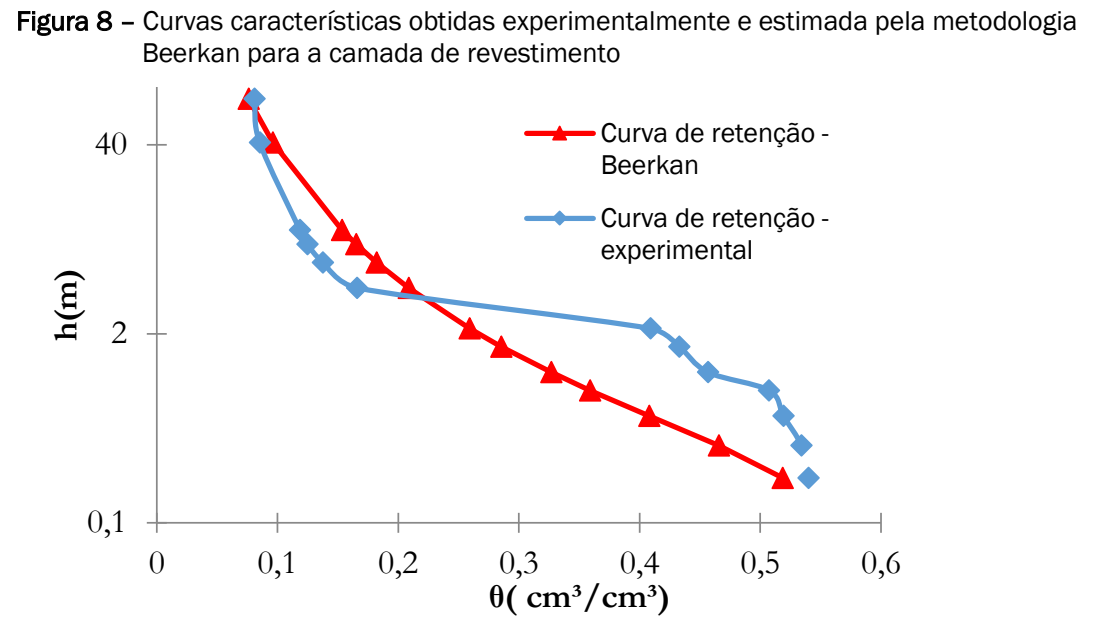

A diferença entre as curvas de retenção pode influenciar significativamente nos resultados de simulações numéricas baseadas na equação de Richards (1931) para a estrutura do pavimento. Uma vez que, para um melhor entendimento dos fluxos de água da camada de revestimento para a camada de reservatório e desta última para o subleito, serão necessárias, além de uma condição inicial estabelecida, o conhecimento da curva de retenção da água no solo e da curva de condutividade hidráulica em função da umidade.

Para esses casos, utilizar as curvas obtidas pelo Beerkan e as curvas obtidas experimentalmente conduzirão as diferenças que necessitam ser verificadas quanto a sua relevância a nível de modelagem numérica. A princípio, o fator tempo é o grande diferencial ao serem utilizadas as curvas de retenção obtidas pelo Beerkan e pelo método experimental.

No entanto, deve-se levar em consideração que a curva obtida com o Beerkan está relacionada com o processo de umedecimento, uma vez que é gerada a partir de um ensaio de infiltração. Enquanto a curva experimental obtida com o Funil de Buchner e com a câmara de Richards são resultantes de contínua secagem de amostras com o aumento de pressões de sucção. Dessa forma, nota-se indícios do fenômeno de histerese entre as curvas obtidas com dois processos.

\subsection{Modelagem Bidimensional}

A Figura 9B demonstra o fluxo de drenagem médio na base da seção bidimensional utilizada. O fluxo apresenta uma dinâmica diária que segue o comportamento da precipitação. A partir dessa simulação há um fluxo máximo de recarga de até $26,55 \mathrm{~L} /$ dia (2,017 \% do total precipitado), valor estimado para o dia 203, o qual possui a maior precipitação no período do estudo, na ordem de 109,7 mm.

Os potenciais totais na superfície apresentam uma variação bem maior que os potenciais totais médios na base da seção (Figura 9B). No entanto, observa-se que a superfície tende a apresentar valores de potenciais mais baixos e, portanto, mais próximos a saturação.

São apresentadas cartas das umidades volumétricas simuladas paras os dias 44, 202 e 203. Esses dias foram escolhidos por apresentarem os eventos de maior precipitação diária para a série utilizada.

A carta do dia 44 é resultado da ação de um fluxo diário de 2,12 m/dia, sendo equivalente a uma precipitação pluviométrica de 97,4 mm. Para esse caso, a precipitação pluviométrica é desprezível nos 11 dias que antecedem o evento (total acumulado de 0,2 mm), gerando uma condição de baixa umidade que pode ser observada no cenário do dia 41 (Figura 10A). 
Figura 9 - Fluxo de drenagem na base da seção (A) e comparação entre o potencial total na superfície do pavimento permeável e o potencial total na base da seção (B)

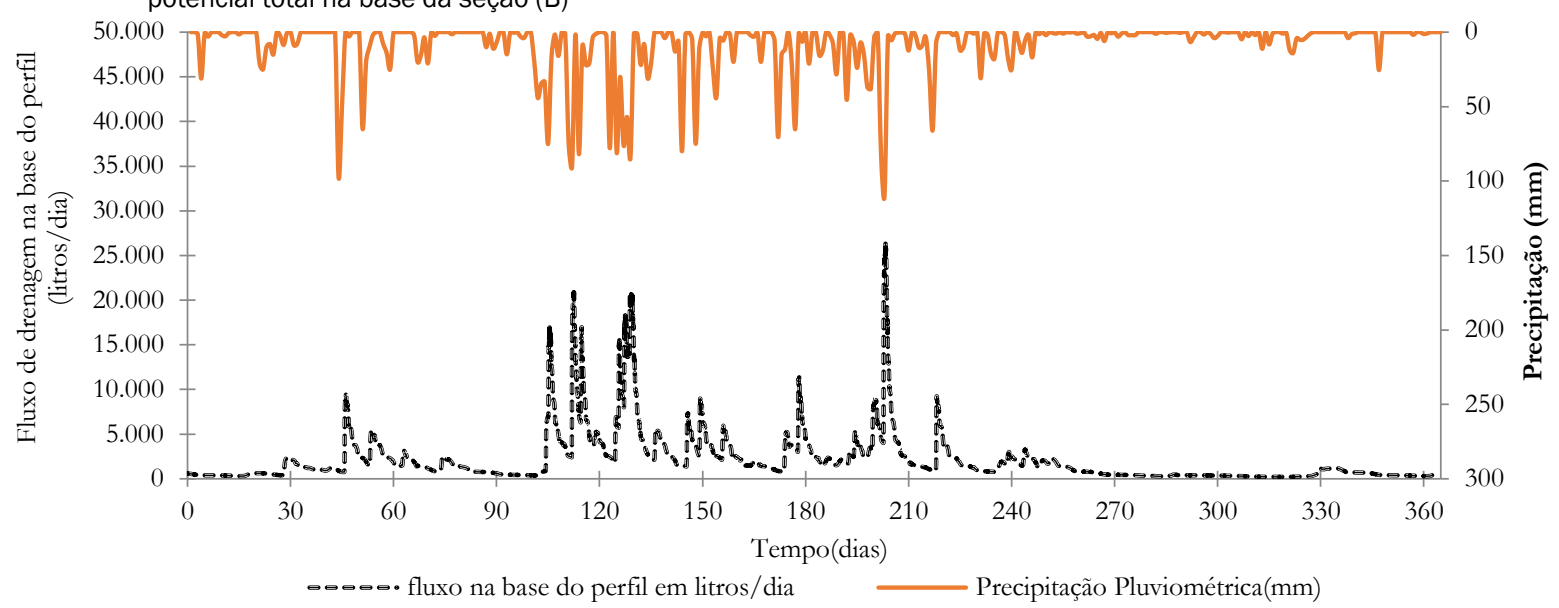

(A)

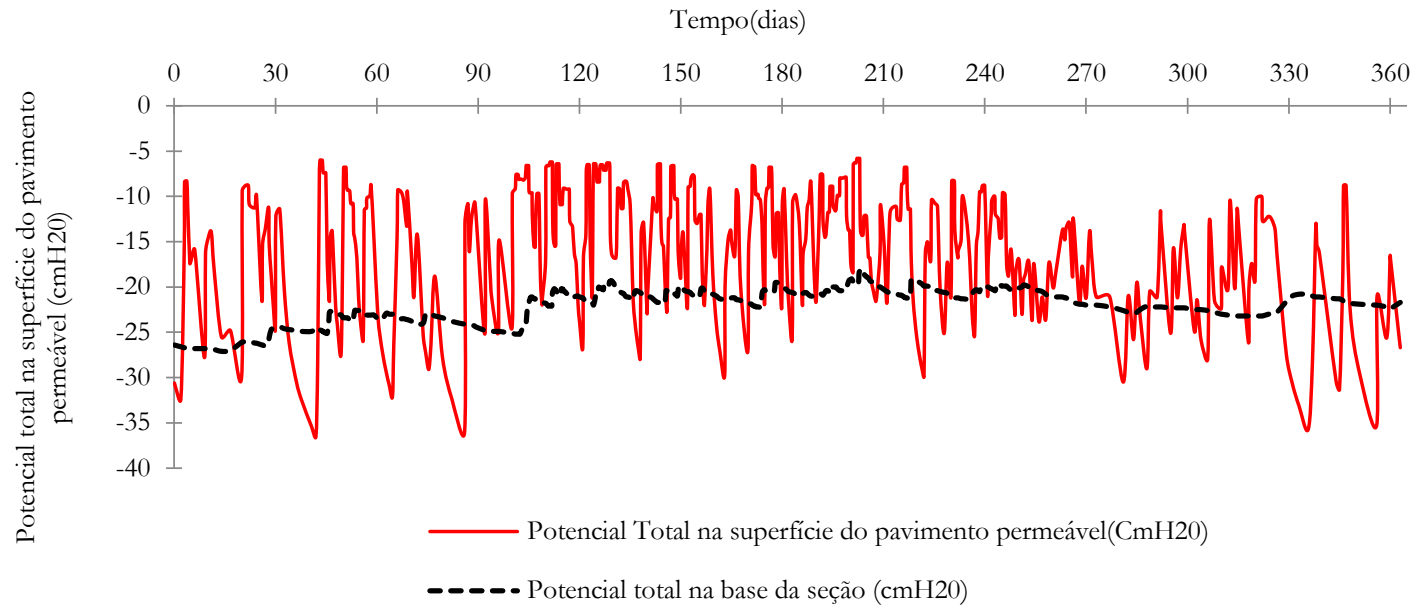

(B)

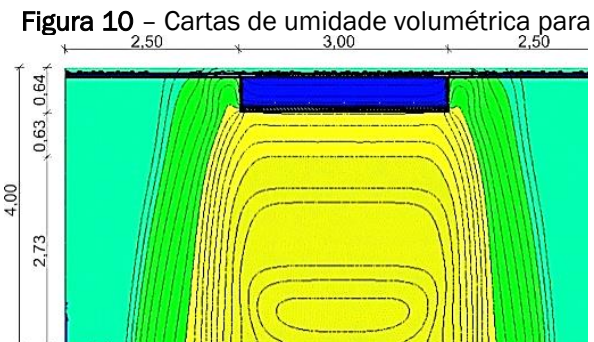

(A)

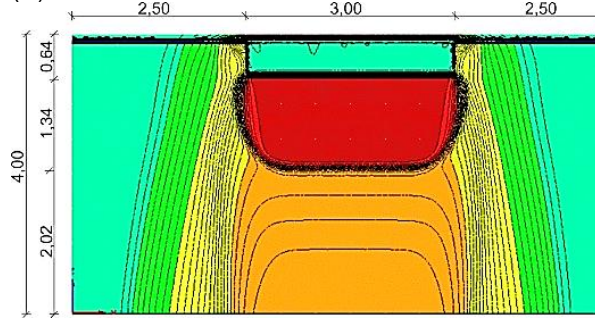

(C)

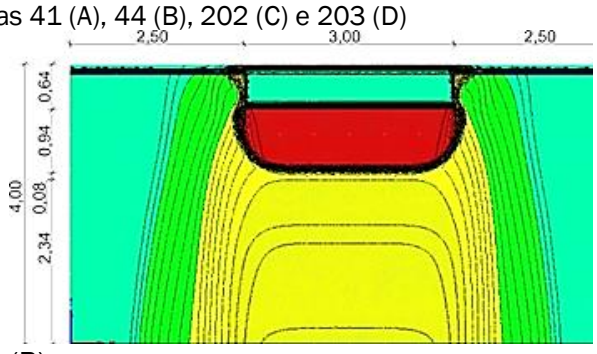

(B)

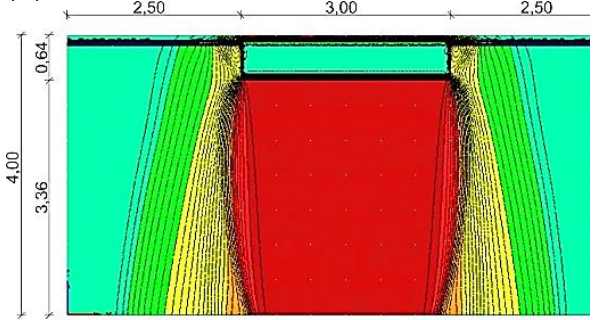

(D)
Após o evento do dia 44, observa-se uma saturação de região imediatamente abaixo do pavimento permeável, evidenciando a importância da camada de fundo do experimento na infiltração (Figura 10B). Além disso, ocorre uma ligeira saturação de 
um pequeno trecho das paredes do dispositivo, sendo a distribuição de umidade na seção bastante simétrica. Tal fato também foi observado por Silva et al. (2009) na análise numérica de um pavimento permeável com camada de reservatório de $15 \mathrm{~cm}$ de profundidade, com subleito de textura argilosa.

Os eventos dos dias 202 e 203 representam o período mais crítico da série de precipitação pluviométrica utilizada, com precipitações de 83,4 e 109,7 mm, e fluxos de entrada de 1,81 e 2,39 m/dia, respectivamente (Figura 10C). Esses eventos ocorrem em condições de solo úmido, uma vez que as precipitações totais acumuladas dos 10 dias anteriores equivalem 178,4 mm. Para esses casos, observa-se que o evento saturou uma área na base da trincheira maior que a apresentada para o dia 44.

No caso do dia 203, observa-se uma saturação completa do solo abaixo do pavimento permeável (Figura 10D). Nota-se também em todos os casos, uma contribuição muito menor das paredes laterais do dispositivo. Possivelmente, um aumento da profundidade melhoraria a drenagem lateral, no entanto, fica demonstrado que a adoção de um comprimento de base maior que a altura privilegia a drenagem, o que é uma consequência do maior efeito da gravidade no escoamento. Além disso, o subleito do pavimento piloto apresenta uma predominância da textura areia, isso permite uma melhor conexão hidráulica dos poros que participam do processo de redistribuição da água no solo. Outra questão é a relação entre a largura da base e a altura das paredes $(\mathrm{L} / \mathrm{H}=4.69)$, essa relação indica uma maior área para infiltração pelos fundos que para infiltração lateral, assim, indicando um privilégio da infiltração pelos fundos em face da infiltração lateral.

Lllgen et al. (2007) realizaram uma simulação bidimensional, resolvendo a equação de Richards para um pavimento permeável em escala piloto submetido a chuva simulada. Segundo os autores, o conteúdo de água no solo no início de um evento de chuva também está influenciando os processos de infiltração no pavimento permeável, mas em um nível muito mais baixo do que para os solos naturais.

Turco et al. (2017) usaram o Hydrus para propor técnicas e procedimentos a fim de interpretar o fluxo de água em um PP em escala de laboratório submetido à diversos eventos de chuva através de 12 sprinklers. Os autores verificaram que a desaturação não ocorre de maneira rápida, enquanto a capacidade de retenção do material é baixa.

Na realidade, um conteúdo relativamente alto de água no solo reduz a maior capacidade de infiltração normalmente observada no início de um evento de chuva, causando taxas de infiltração mais baixas, gerando, no entanto, uma maior uniformidade de infiltração e avanço da frente de molhamento.

\section{CONCLUSÕES}

A camada de revestimento apresentou elevadas taxas de infiltração. Os resultados obtidos através da metodologia Beerkan permitiram um melhor detalhamento das propriedades das camadas do revestimento e do subleito do pavimento permeável. No caso, a condutividade hidráulica saturada apresentou resultados satisfatórios, indicando assim, a eficiência do dispositivo piloto em atuar, quantitativamente, como dispositivo viável para a infiltração das águas pluviais.
A camada de revestimento ficou submetida à ação mecânica direta dos pneus dos veículos (veículos de passeio com baixa velocidade). Ainda assim, a capacidade de infiltração da camada superficial do revestimento apresentou-se satisfatória.

Os ensaios de infiltração foram realizados em condições reais de funcionamento, sujeito a ação de agentes que tendem a prejudicar seu funcionamento hidráulico como folhas de árvores, sedimentos carreados pela água de escoamento superficial, e resíduo difuso.

No que tange a modelagem bidimensional, as simulações demonstram que o dispositivo apresenta uma maior redistribuição de umidade a partir da cama de fundo do experimento.

\section{AGRADECIMENTOS}

Este trabalho foi realizado com o apoio do projeto "Transferência de Água e Misturas de Poluentes Reativos em Solos Antropizados" (Processo CNPq n 436875 / 2018-7).

\section{REFERÊNCIAS}

AMERICAN SOCIETY FOR TESTING AND MATERIALS - ASTM. ASTM D3385: Standard Test Method for Infiltration Rate of Soils in Field Using Double-Ring Infiltrometer, 2018.

ALCÂNTARA, L. R. P.; MARTINS, L. A.; COSTA, I. R. A.; OLIVEIRA, V. H. O.; SANTOS NETO, S. M.; COUTINHO, A. P.; ANTONINO, A. C. D. Avaliação de modelos probabilísticos para chuvas intensas nas mesorregiões do estado de Pernambuco. Journal of Environmental Analysis and Progress, v. 4, n. 1, p. 90-103, 2019.

https://doi.org/10.24221/jeap.4.1.2019.2332.090-103

AGÊNCIA PERNAMBUCANA DE ÁGUAS E CLIMA ÁGUAS - APAC. Sistema de Geoinformação Hidrometeorológico de Pernambuco. Disponível em: http://www.apac.pe.gov.br/sighpe/. Acesso em: 26 abr. 2020.

ARAUJO, P. R., TUCCI, C. E. M., GOLDENFUM, J. A. Avaliação da Eficiência dos Pavimentos Permeáveis na Redução de Escoamento Superficial. Revista Brasileira de Recursos Hídricos, v. 5, n. $3, \quad$ p. $21-29, \quad 2000$. https://doi.org/10.21168/rbrh.v5n3.p21-29

ASSOCIAÇÃO BRASILEIRA DE NORMAS TÉCNICAS - ABNT. NBR 7181: solo - análise granulométrica. Rio de Janeiro, 2016.

AZZOUT, Y., BARRAUD, S., CRES, F. N., ALFAKIH, E. Techniques alternatives en assainissement pluvial: choix, conception, realization et entretien. Paris: Lavoisier, 1994. 372p.

BAI, T., MAYER, A. L., SHUSTER, W., TIAN, G. The Hydrologic Role of Urban Green Space in Mitigating Flooding (Luohe, China). Sustainability, v. 10, n. 10, 2018. https://doi.org/10.3390/su10103584

BONNEAU, J., FLETCHER, T. D., COSTELLOE, J. F., BURNS, M. J. Stormwater infiltration and the 'urban karst'. A review. Journal of hydrology, v. 552, p. 141-150, 2017. https://doi.org/10.1016/i.jhydrol.2017.06.043

BROOKS, R. H., COREY, A. T. Hydraulic properties of porous media. Hydrology Paper, n 3, Fort Collins: Colorado State University, 1964. 27p. 
BURDINE, N. T. Relative permeability calculations from pore size distribution data. Transactions of the Society of Petroleum Engineers of AIME, v. 198, p.71-78, 1953. https://doi.org/10.2118/225-G

CABRAL, J. J.S. P; MONTENEGRO, S. M. G. L. Considerações sobre a salinização dos aqüíferos costeiros na Planície do Recife. In: CABRAL, Jaime Joaquim da Silva Pereira; FERREIRA, João Paulo Lobo; MONTENEGRO, Suzana Maria Gico Lima (Orgs.). Água subterrânea: aqüíferos costeiros e aluviões, vulnerabilidade e aproveitamento. Recife: Editora Universitária, 2004, v. 1, p. 150- 188.

CHANDRAPPA, A. K., BILIGIRI, K. P. Pervious concrete as a sustainable pavement material: research findings and future prospects: A state-of-the-art-review. Construction and Building Materials, v 111, p. 262-274, 2016.

https://doi.org/10.1016/i.conbuildmat.2016.02.054

CHU, L., FWA, T. F. Evaluation of surface infiltration performance of permeable pavements. Journal of Environmental Management, v. 238, 136-143, 2019.

https://doi.org/10.1016/j.jenvman.2019.02.119

DRAKE, J., BRADFORD, A., VAN SETERS, T. Stormwater quality of spring-summer-fall effluent from three partial-infiltration permeable pavement systems and conventional asphalt pavement. Journal of environmental management, v.139, p. 6979, 2014. https://doi.org/10.1016/i.jenvman.2013.11.056

GOMES, C. A., LIMA, J. R. S., ANTONINO, A. C. D.; SOARES, W. A., SOUZA, E. S., RIBEIRO, A. A.,; ALVES, E. M., MACHADO, C. B., FIRMINO, F. H. T. Medição e Simulação dos Fluxos de Energia e Evapotranspiração em Solo Cultivado com Brachiaria decumbens na Microrregião de Garanhuns-PE. Revista Brasileira de Geografia Física, v. 8, n. 2, p. 365-376, 2015.

HAVERKAMP, R., PARLANGE, J. Y. Predicting the water retention curve from particle distribution: 1 . Sandy soils without organic matter. Soil Science, v. 142, n 7, p. 325-335, 1986. https://doi.org/10.1097/00010694-198612000-00001

HAVERKAMP, R., ROSS, P. J., SMETTEM, K. R. J., PARLANGE, J. $Y$. Three dimensional analysis of infiltration from the disc infiltrometer. 2. Physically based infiltration equation. Water Resources Research, v. 30, p. 2931-2935, 1994. https://doi.org/10.1029/94WR01788

HOLANDA, M. A. C. R., SOARES, W. A. Analysis of the effect of impermeability of urban soils on the infiltration of rainwater in the city of Recife, PE. Ambiente \& Água, v. 14, n. 4, 2019. https://doi.org/10.4136/ambi-agua.2386

HUNT, F. W. Working with regulators to change Permeable Pavement Acceptance. In: INTERNATIONAL CONFERENCE ON CONCRETE BLOCK PAVING, 9., 2009. Buenos Aires, Argentina, 2009/10/18-21. [Anais...] Argentinean Concrete Block Association (AABH) - Argentinean Portland Cement Institute (ICPA) Small Element Paving Technologists (SEPT), 2009.

JABUR, A.S., DORNELLES, F., SILVEIRA, A.L.L., GOLDENFUM, J.A., OKAWA, C.M.P., GASPARINI, R.R. Determinação da capacidade de infiltração de pavimentos permeáveis. Revista Brasileira de Recursos Hídricos, v. 20, n. 4, p. 937-945, 2015. https://doi.org/10.21168/rbrh.v20n4.p937-945
JAYARATHNE A., WIJESIRI B., EGODAWATTA P., AYOKO G.A., GOONETILLEKE A. Metals in the urban stormwater environment. in: transformation processes of metals in urban road dust. SpringerBriefs in Water Science and Technology. Springer, Singapore, p. 1-10, 2020. https://doi.org/10.1007/978981-15-2078-5_1

JIANG, W., SHA, A., XIAO, J., LI, Y., HUANG, Y. Experimental study on filtration effect and mechanism of pavement runoff in permeable asphalt pavement. Construction and Building Materials, v. 100, p. 102-110, 2015. https://doi.org/10.1016/i.conbuildmat.2015.09.055

KUMAR, K., KOZAK, J., HUNDAL, L., COX, A., ZHANG, H., In-situ infiltration performance of different permeable pavements in an employee used parking lot: a four year study. Journal of Environmental Management, v. 167, p. 8-14. 2016. https://doi.org/10.1016/i.jenvman.2015.11.019

LASSABATERE, L., DI PRIMA, S., BOUARAFA, S., IOVINO, M., BAGARELLO, V., ANGULO-JARAMILLO, R. BEST-2K Method for Characterizing Dual-Permeability Unsaturated Soils with Ponded and Tension Infiltrometers. Vadose Zone Journal, v. 18, 2019. https://doi.org/10.2136/vzj2018.06.0124

LLLGEN, M., HARTING, K., SCHMITT, T. G., WELKER, A. Runoff and Infiltration characteristics of permeable pavements: review of an intensive monitoring program. NOVATECH 2007, p. 1023-1030, 2007.

LI, C., PENG, C., CHIANG, P., CAI, Y., WANG, X., YANG, Z. Mechanisms and applications of green infrastructure practices for stormwater control: a review. Journal of hydro-logy, v. 568, p. 626-637, 2019.

https://doi.org/10.1016/i.jhydrol.2018.10.074

LIMTHONGSAKUL, S., NITIVATTANANON, V., ARIFWIDODO, S. D. Localized flooding and autonomous adaptation in peri-urban Bangkok. Environment and Urbanization, v. 29, p. 51-68, 2017. https://doi.org/10.1177/0956247816683854

LIU, L.; YAN, H.; LIAO, Z.; ZHANG, K.; SCHMID, A. R.; TAO, T. Laboratory analysis on the surface runoff pollution reduction performance of permeable pavements. Science of The Total Environment, v. 691, p. 1-8, 2019. https://doi.org/10.1016/i.scitotenv.2019.07.028

LIU W., CHEN, W., FENG, Q. Field simulation of urban surfaces runoff and estimation of runoff with experimental curve numbers. Urban Water Journal, v. 15, n. 5, p. 418-426, 2018. https://doi.org/10.1080/1573062X.2018.1508597

MEDEIROS, R. M.; HOLANDA, R. M.; VIANA, M. A.; SILVA, V. P. Climate classification in Köppen model for the state of Pernambuco - Brazil. Revista de Geografia, v. 35, n. 3, p. 219234, 2018.

MORAIS, F. Infiltração: uma variável geomorfológica. Caderno de Geografia, v. 22, n. 38, p. 73-87, 2012.

MUALEM, Y. A new model for predicting the hydraulic conductivity of unsaturated porous media. Water Resources Research, v. 12, p. 513-522, 1976.

https://doi.org/10.1029/WR012i003p00513 
NNADI, E. O., NEWMAN, A. P., COUPE, S. J., MBANASO, F. U. Stormwater harvesting for irrigation purposes: an investigation of chemical quality of water recycled in pervious pavement system. Journal of Environmental Management, v. 147, p. 246256, 2015. https://doi.org/10.1016/i.jenvman.2014.08.020

PAGE, J. L., WINSTON, R. J., MAYES, D. B., PERRIN, C., HUNT, W. F. Retrofitting with innovative stormwater control measures: hydrologic mitigation of impervious cover in the municipal right-of-way. Journal of Hydrology, v. 527, p. 923-932, 2015. https://doi.org/10.1016/j.jhydrol.2015.04.046

PHILIP, J. R. The quasi-linear analysis, the scattering analog, and other aspects of infiltration and seepage. In: FOK, Y. S. (ed.) Infiltration development and application, Honolulu: Water Resources Research Center, p.1-27, 1987.

RICHARDS, L.A. Capillary conduction of liquids in porous mediums. Physics 1, p. 328-333, 1931. https://doi.org/10.1063/1.1745010

RODRÍGUEZ-ROJAS, M. I., HUERTAS-FERNÁNDEZ, F., MORENO, B., MARTÍNEZ, G., GRINDLAY, A. L. A study of the application of permeable pavements as a sustainable technique for the mitigation of soil sealing in cities: A case study in the south of Spain. Journal of environmental management, v. 205, p. 151162, 2018.

\section{https://doi.org/10.1016/i.jenvman.2017.09.075}

SANTOS, K. A., RUFINO, I. A. A., BARROS FILHO, M. N. M. Impactos da ocupação urbana na permeabilidade do solo: o caso de uma área de urbanização consolidada em Campina Grande - PB. Engenharia Sanitária e Ambiental, v. 22, n. 5, p. 943-952, 2017. https://doi.org/10.1590/s141341522016146661

SELBIG, W. R.; BUER, N.; DANZ, M. E. Stormwater-quality performance of lined permeable pavement systems. Journal of Environmental Management, v. 251, p. 1-13, 2019. https://doi.org/10.1016/j.jenvman.2019.109510

SILVA, G. B. L.; MOURA, T. A. M.; KOIDE, S.; CAMPANA, N.A. Avaliação da Infiltração em Revestimentos com Superfícies Permeáveis. Ingenieria del Água, v. 16, n 3, p. 175-188, 2009. https://doi.org/10.4995/ia.2009.2953

SIMUNEK, J., VAN GENUCHTEN, M.TH., SEJNA, M. Development and applications of the HYDRUS and STANMOD software packgages and related codes. Vadose Zone Journal, v.7, p.587-600, 2008.

https://doi.org/10.2136/vzj2007.0077

SOIL CONSERVATION SERVICE (SCS). National engineering handbook: Section 4, Hydrology, 1972.

SOUZA, E. S., ANTONINO, A. C. D., LIMA, J. R. S., NETO, G. C. G., SILVA, J. M., SILVA, I. F. Efeito do encrostamento superficial nas propriedades hidráulicas de um solo saturado. Revista Brasileira de Ciências Agrárias, v. 2, n.1, p. 69-74, 2007. https://doi.org/10.5039/agraria.v2i1a406

SOUZA, E. S.,; ANTONINO, A. C. D., ÂNGULO-JARAMILO, R., NETTO, A. M. Caracterização hidrodinâmica de solos: Aplicação do método Beerkan. Revista Brasileira de Engenharia Agrícola e Ambiental, v. 12, n. 2, p. 128-135, 2008. https://doi.org/10.1590/S1415-43662008000200004

TURCO, M., KODEŠOVÁ, R., BRUNETTI, G., NIKODEM, A., FÉR, M., PIRO, P. Unsaturated Hydraulic behaviour of a permeable pavement: Laboratory investigation and numerical analysis by using the Hydrus-2d Model. Journal of Hydrology, v. 554, p. 780-791, 2017.

https://doi.org/10.1016/i.jhydrol.2017.10.005

VAN GENUTCHEN, M. Th. A closed-form equation for predicting the hydraulic conductivity of unsaturated soils. Soil Science Society of American Journal, v. 44, n. 5, p. 892 -898, 1980. https://doi.org/10.2136/sssaj1980.03615995004400050 $\underline{002 x}$

WINSTON, R. J., AL-RUBAEI, A. M, BLECKEN, G. T., VIKLANDER, M., 2016. Maintenance measures for preservation and recovery of permeable pavement surface infiltration rate - the effects of street sweeping, vacum cleaning, high pressure washing, and milling. Journal Environmental Management, v. 169, p. 132-144, 2016. https://doi.org/10.1016/i.jenvman.2015.12.026

WHITE, I., SULLY, M. J. Macroscopic and Microscopic capillary length and times scales from field infiltration. Water Resources Research, v. 23, n. 8, p. 1514-1522, 1987. https://doi.org/10.1029/WR023i008p01514

ZHU, H., YU, M., ZHU, J., LU, H., CAO, R. Simulation study on effect of permeable pavement on reducing flood risk of urban runoff. International Journal of Transportation Science and Technology, v. 8, p. 373-382, 2019.

https://doi.org/10.1016/j.ijtst.2018.12.001 